\title{
Specific and Optional Curriculum: An Experience in the Undergraduate Program of Chemical Engineering in Cienfuegos University, Cuba
}

\author{
Yolanda García Martínez*, Claudia Alvarado Velázquez, Rolando Delgado Castillo \\ Department of Chemical Engineering, Engineering Faculty, University of Cienfuegos, Cuba
}

Copyright@2016 by authors, all rights reserved. Authors agree that this article remains permanently open access under the terms of the Creative Commons Attribution License 4.0 International License

\begin{abstract}
This paper pursues to define the pillars for designing the specific (SC) and optional curricula (OC) of Unit Operations and Processes (UOP) Discipline in the Chemical Engineering Program. To achieve this objective a methodology was developed, which was characterized by the participation of every member in the educational process: professors, experts of industrial sector and students. The joint work made it possible to carry out a variety of tasks: the characterization of regional industries according to the academic requests of the UOP discipline, the identification of deficiencies in the basic curriculum (BC), the needs of industries in environmental matters and the students' preferences in their optional professional formation. The result of this qualitative study expressed a high convergence of all the variables under study. The importance of arranging SC and OC was validated, among other important alternatives, towards environmental technologies. These subjects combine important contents in the academic order with significant contributions to solve imperative problems of the territory. The significance of taking into account the strategic matters associated with Biotechnology, Petroleum Technology, and Food Technologies, key subjects for indispensable development of our regional context, was also recognized.
\end{abstract}

Keywords Engineering Curriculum, Curriculum Design, Optional Curriculum

\section{Introduction}

The different kinds of Optional/Elective Curriculum offered in contemporary Higher Education Institutions constitute one of the most relevant components in the professional formation [1].

The competences of the graduates must show a universal academic level and at the same time they must respond to the needs of the social context in which the new professional will be inserted [2].

In American Universities can be observed as trend the presence in the Study Plans of "required courses" for all students in the program, elective courses (often referred as open or free electives) that present optional character and other elective courses of which students must select one or more courses from a specified group [3].

Due to diversity of terms, the multiple meanings of the concepts and the variety of approaches that characterize contemporary higher education, we consider necessary to set out some principles, ideas and concepts that direct the formation processes in Cuban universities.

The Higher Education Ministry (HEM) [4]:

Establishes as key ideas for addressing the processes of professional training: The unity between instruction and education and the narrow relation between study and work.

Prescribes a professional model of wide profile, whose essential quality is a deep basic formation, with mastery of the essential aspects for their professional practice.

Defines three kinds of curricula: Basic (BC); Specific (SC) and Optative-Elective (OC).

A National Commission for each Undergraduate Program adapts these guidelines and proposes to Universities, giving ample flexibility, a specimen of Study Plan with mandatory contents (BC). Additionally, this Commission characterizes every element of professional model [5]. For example, the National Commission of Undergraduate Chemical Engineering Program (NCCheE) is chaired by the Chemical Engineering Department of University of Oriente, which in 1947 opened the first Cuban program of this engineering.

The design of the SC and OC is prepared by the Collective of Discipline, belonging to Department of each university. Later the Undergraduate Program Council (UPC) considers the pertinence of proposals according to the social determinants of context, the strengths of the academic faculty, and the legitimate preferences of the students. Ideally, this triangle should define these specific and optional-elective courses. Nevertheless, from our view to achieve a harmony between social and academic pertinence 
must be developed something more than a methodological work of "experts". It is a real problem facing the contemporary universities, especially in Latin American scenarios [6]. Thus, the objective of this paper is to develop a methodology that, taking into account the criterions of participants, allows the integration of the needs of local industry with the update and academic pertinence of the subjects in the planning of Specific (SC) and Optional Curricula (OC).

Table 1 resumes the main interactions that occur between the different institutions of the Cuban higher education system, which are related to the limited scope and the objectives pursued by this work.

The selection of the Unit Operations and Processes (UOP) Discipline for carry out this experience is relating with its importance in the formation of Chemical Engineer and consequently its outstanding position in the Study Plan.

Today the study of Discipline Unit Operations and Processes constitutes a main core of the Chemical Engineering Programs [7]. Just the foundational period of this career is associated with this discipline. At that moment, in the booming industrial English context, George Edward Davis (1850-1906) - industrial chemist and professor of Manchester Technical School - arrives to a conclusion of extraordinary didactic value: the diversity of chemical industrial processes have as common elements, as expression of its organic unity, certain operations and process. Thus Davis discovered the core concept for founding a new profession and its first study plan [8]. The continuous improvement of this discipline is associated to greatest achievements of Chemical Engineering [9, 10].

The figure 1 offers the distribution of workload (in $\%$ of total time) assigned to Careers Discipline.

Perhaps, it being convenient remark that Program Criteria for Chemical Engineering Technology established by the Engineering Technology Accreditation Commission of ABET [11] defines: "The program must demonstrate that graduates have the ability to apply: The concepts of chemical engineering unit operations such as mass transfer, heat transfer, distillation, and evaporation to the design, operation, and maintenance of chemical processes..."

The differences in social development, technological level and material achievements, don't interfere in the observance of the universal character of students outcomes. Any contemporary program pursues professional competences such as: An understanding and responsibility to encourage professional and ethical values including, respect for diversity and knowledge of the impact of engineering technology in a social and global context [12]. These thesis are also assumed by our methodology.

Table 1. Regulations and steps in the curriculum construction

\begin{tabular}{|c|l|}
\hline & The workload for the BC has to be $>70 \%$ and $<80 \%$ of total time. The OC workload have to be $>10 \%$ of total \\
H. & time without breaking previous guideline. \\
E. & A system approach organizes the program horizontally by academic year and vertically by academic disciplines. \\
M. & $\begin{array}{l}\text { An integrative core discipline (ID) is developed from first to fifth year, covering approximately a third of the total } \\
\text { curriculum. Its essence is direct research-work. }\end{array}$ \\
\hline N. & The basic contents are established with mandatory character and the disciplines of BC are characterized. \\
C. & Nevertheless, the number of subjects, their syllabus and distribution have a suggest character. \\
Ch. & The integrative core discipline of ChEUP is Engineering of Processes. \\
E. & The semester distribution of subjects, according to proposals of Principal Professors of Disciplines, is approved. \\
U. & The SC and OC of each discipline are considered. \\
P. & ID presents the research - work planning in the local industries for each academic year and the interdisciplinary \\
C. & relationships. \\
\hline
\end{tabular}

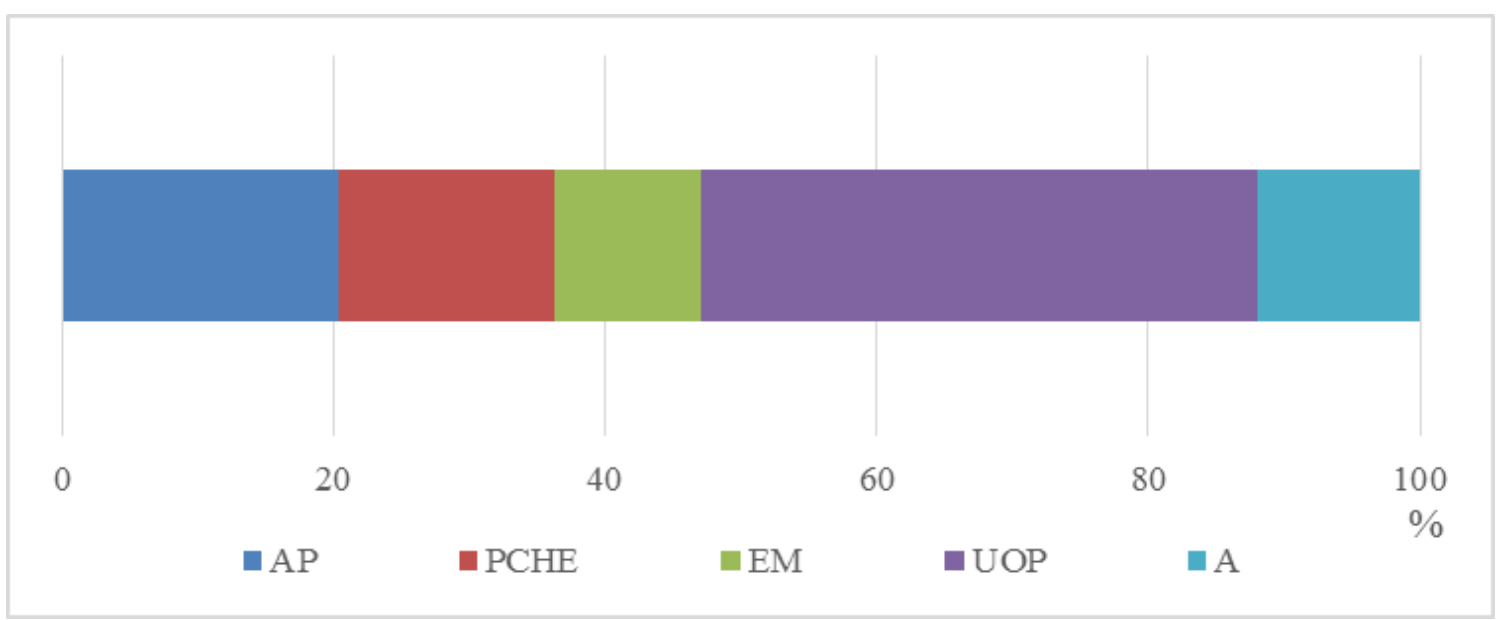

AP: Analysis of Processes, PChE: Principles of Chemical Engineering: EM: Engineering of Materials; A: Automation.

Figure 1. Relative workload of Engineering Disciplines 


\section{Methodology}

This paper belongs to qualitative method in educational research [13] within the framework of the historic-cultural approach.

The authors share the idea that a curriculum sustained in this approach essentially should:

Formulate objectives that respond to social and professional requirements, from the most general tasks in an essential way for achieving cultural, ethical and professional competences [14].

Focus the educational process in the activity of the students by means of their interaction with the object of knowledge, the collaboration and social orientation [15].

Guarantee flexibility that take account the particularities and needs of students and the teaching-learning situations [16].

This study was developed through the course 2014 2015 as part of Degree Thesis of Chemical Engineering Program inserted in the project of the department for developing curricular researches.

The inquests applied had a unique and simple format that invites to answer by means of selection between five options: very adequate (v.a.), quite adequate (q.a), adequate (a.), not very adequate (n.v.a.) and inadequate (i) corresponding to a range of valuation between $5-1$.

The interviews only were made for explaining some results which the authors would like to go deeply. They had non-structured format and sometimes had a collective participation.

The Delphi method proposed by Hurtado [17] was applied as an initial validation of methodology and for obtaining the opinions of "external" experts about our final proposals. It demands only one experts' round. A Panel of Experts was integrated for twelve Titular Professors (Doctors in Science) with an elevated experience in university teaching and environmental research: Four members of Study Center of Energy and Environment, four associates to Clean Production Group and four colleagues of Mechanical Department who develop joint work with our department. They show in consequence an elevated competence coefficient.

Table 2. Characteristics of participants

\begin{tabular}{|c|c|c|c|}
\hline \multirow{3}{*}{ Participant } & \multicolumn{3}{|c|}{ Characteristic } \\
\hline \multirow{4}{*}{ Professors } & Category & number & $\%$ \\
\cline { 2 - 4 } & Doctor & 3 & 20 \\
\cline { 2 - 4 } & Master & 8 & 53,3 \\
\cline { 2 - 4 } & Titular & 3 & 20 \\
\cline { 2 - 4 } & Associate & 3 & 20 \\
\cline { 2 - 4 } & Assistant & 9 & 60 \\
\hline \multirow{4}{*}{ Experts of } & Experience & $>5$ years \# \% & $>10$ years \\
\cline { 2 - 4 } & Plant Head & $6-40 \%$ & $9-60 \%$ \\
\hline \multirow{3}{*}{ Students } & Course & Number & $\%$ \\
\cline { 2 - 4 } & 3th & 10 & 42,8 \\
\cline { 2 - 4 } & 4th & 18 & 33,2 \\
\cline { 2 - 4 } & 5th & 14 & \\
\cline { 2 - 4 } & & & \\
\hline
\end{tabular}

Table 2 indicates the significant sample of every participant.

The professors constitute an $88.2 \%$ of total that develop the disciplines of chemical engineering and reflect the professional pyramid of our department. The experts work in 14 local industries in which are inserted our students in pre-professional practice. In particular, three engineers of Oil Refinery are participant and at the same time are part-time lecturers. The registration number of students of these courses is 23 in 3 th, 28 in $4^{\text {th }}$ and 21 in $5^{\text {th }}$, therefore the participant represents more than $55 \%$.

\subsection{Principles and Procedures}

We want to direct our experience with a democratic character, so that the different participants in the educational process are fully identified with this study and the results reflect objectively their honest opinions, trying as far as possible to converge the differences and otherwise interpret the causes of agreements and discrepancies.

Hence, the following working guidelines were accepted:

The initial acceptance to be part of integrated research teams.

Equal rights to take part in the analysis and express their views.

The atmosphere of respect must be assumed during visits to industries.

Indicators and research tasks must be approved by the majority of participants.

The quantitative treatment of the results is essential but the significance for the people is the most important.

The line of thought that we deal with is to try to integrate academic and social relevance in the optional curriculum of OUP discipline.

\subsection{Main Tasks}

The tasks addressed in the study show a triple perspective: The methodological design of the research, analysis of UOP in the BC and the needs of local industry, and the review of trends in the elective curriculum program of chemical engineering in national and foreign universities. Starting views and results achieved were submitted for consideration by a board of experts. As follows these tasks are related:

Select the work indicators.

Construct the methodological instruments for inquiring and processing the criterions.

Elect the professors, experts of local industries and students, which take part in the investigation.

Identify an inventory of UOP in the local industry and the lacks in the $\mathrm{BC}$.

Search of pertinent national and foreign programs of UOP in elective curriculum.

Recognize local industrial needs in technical and environmental issues.

Evaluate the pertinence of subjects proposed for SC and OC according to expert's method. 
Assess availability in technical and learning resources for the subjects proposed.

\subsection{Indicators}

The proposed objective determines the convenience of finding: the self-evaluation of participants on their potential contribution towards this research; deficiencies in the subjects of the UOP discipline (BC) according to the needs of local industries; appropriate contributions from consideration of trends in national and international programs; the significance given to environmental problems of the territory. As a matter of fact the indicators are the following:

Vision of participants about their respective roles in the curricular design.

Deficiencies of BC in the subjects of UOP discipline.

Importance for the local industrial needs.

Pertinence of specific and optional programs offered for other national and foreign universities in our context.

Significance conferred to environmental problems in the $\mathrm{SC}$ and the OC.

Pertinence of promising technologies for offering in the $\mathrm{SC}$ and $\mathrm{OC}$ of the UOP discipline.

\section{Results and Discussion}

\subsection{Vision of Participants about their Respective Roles in the Curricular Design}

As shown in Figure 2a, self-assessment made by professors of the department on competence to develop programs of SC and OC, is more than $30 \%$ between quite adequate and appropriate (which coincides with the professors' experience). The industry experts, meanwhile, give a higher rate since almost $90 \%$ assess the competence of professors to fulfill this task from very adequate and quite adequate. Students place their opinion among quite adequate and very adequate $(75 \%)$.

The recognition of professors about the importance of the expert's opinions is very high, and the self-evaluation of experts attain a maximum for the rate quite adequate, whereas more than $60 \%$ of the students judge as quite adequate or very adequate the significance or expert's opinions (Figure 2b).

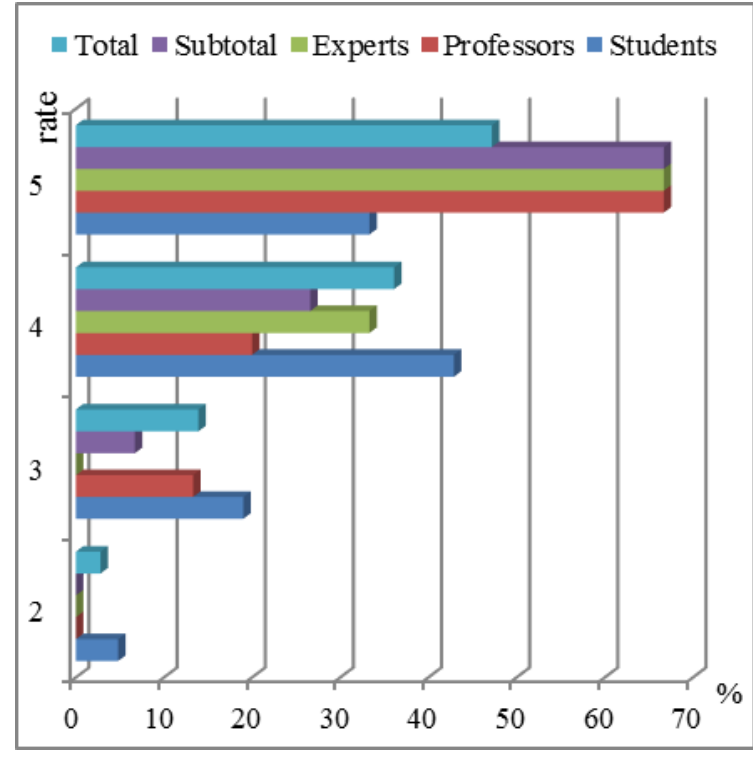

Figure 2a. Competence of Professors

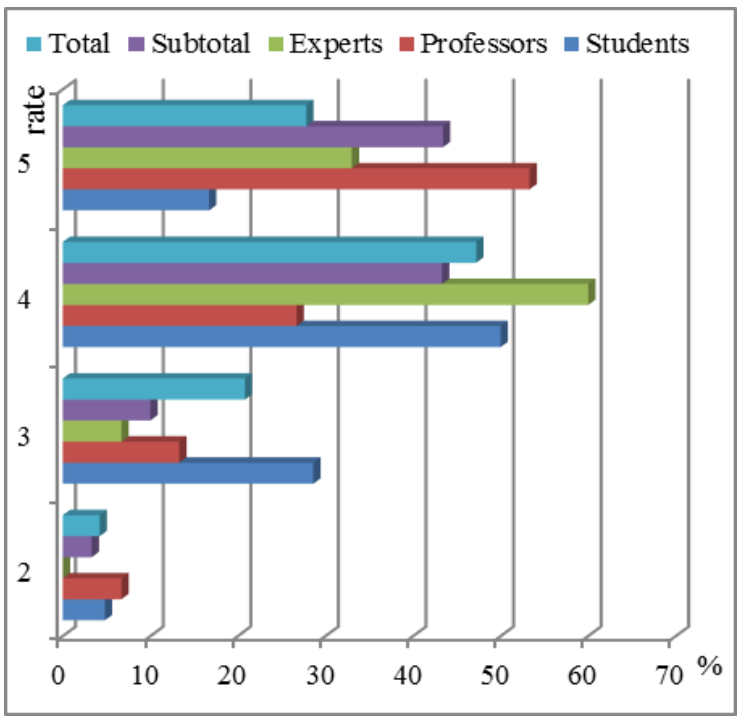

Figure 2b. Experts of Industries

In the figure $2 \mathrm{c}$ can be observed the notable divergence between the opinions of professors (less than $50 \%$ considers as very adequate or adequate this question) whereas the $100 \%$ of students evaluate as very adequate their preferences. The inquiries to professors reveal the predominant criterion about the limitations of the view of students about existing resources and availability of professors. The experts of industries believe that the preferences of students are a very important factor when almost $100 \%$ evaluates this point as very adequate or quite adequate. 


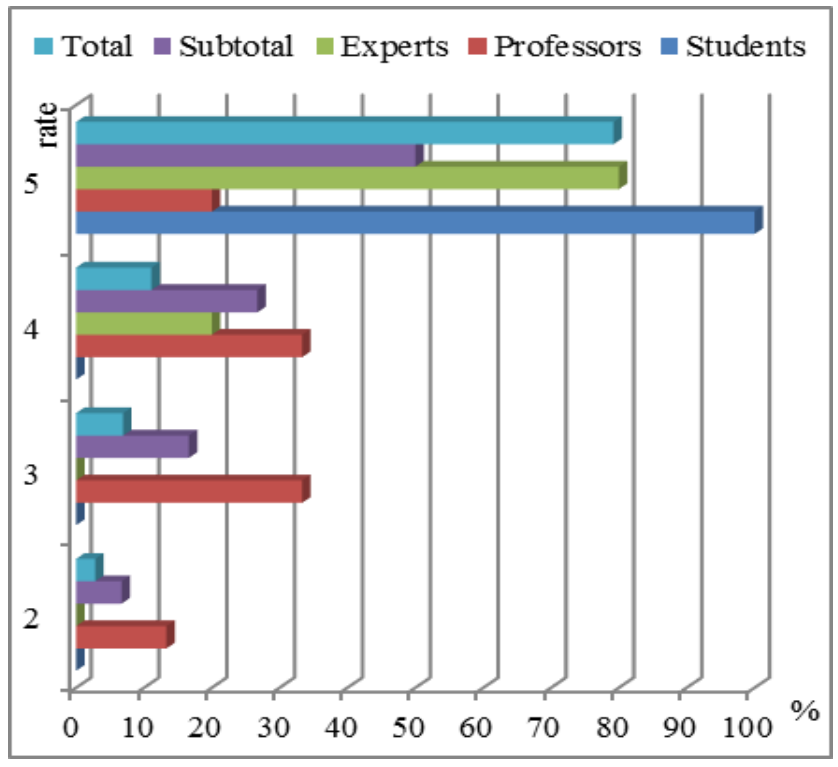

Figure 2c. Preferences of students
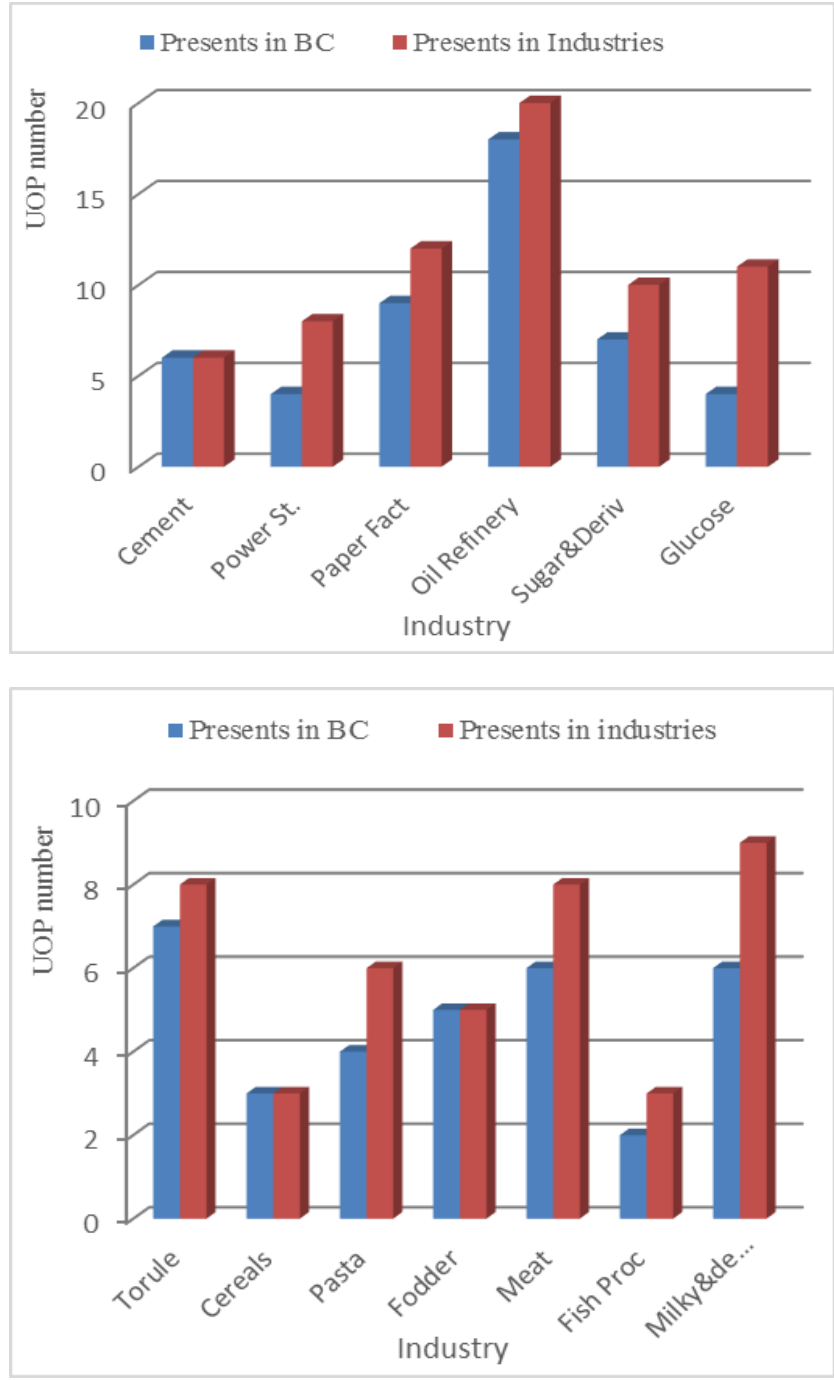

Figures 3a and 3b. Lacks of UOPs in BC

\subsection{Local Industrial Sector from Perspective of UOP- Basic Curriculum}

The figures $3 a$ and $3 b$ show the deficiencies of the UOP in 13 local industries which our department has collaboration with and the students of Chemical Engineering Program make different researches of technological innovation.

These figures lead to identify a total of 39 UOP in local industries of which only $41 \%$ are included in the BC. An analysis of how the lacks are distributed in different subjects of discipline is showed in Figure 3c. This figure reveals that subjects Mass Transfer, Energy Transfer and Mechanical Separations of the UOP discipline in the BC focus the main deficiencies. For example, in the case of Mass Transfer, the subject with the biggest lack, important UOPs such as dialysis, electro-dialysis, reverse osmosis, adsorption, ion exchange, chromatography, and electrophoresis don't appear in the curriculum.

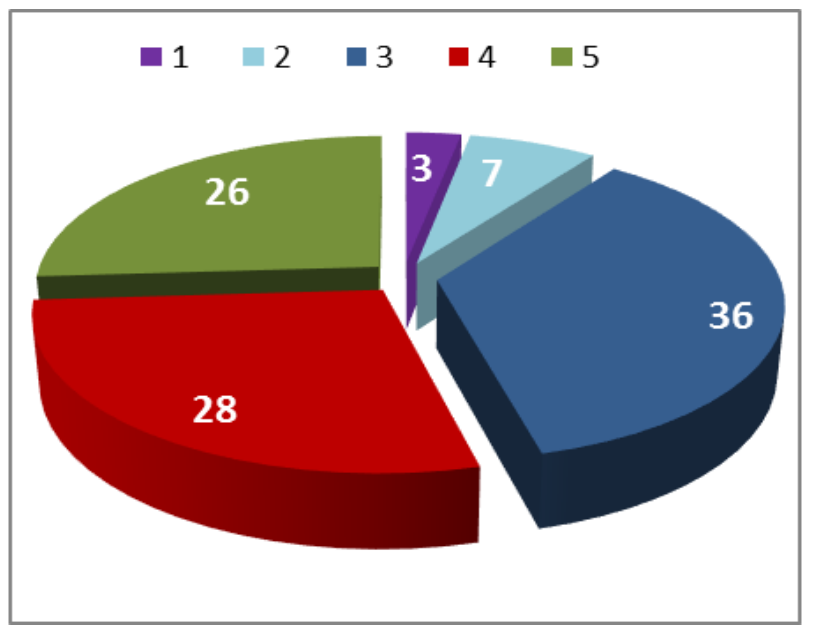

1: Flux of Fluids; 2: Reactors; 3: Mass Transfer; 4: Energy Transfer; 5: Mechanical Separations

Figure 3c. Distribution of deficiencies for subjects of UOP discipline (\%)

\subsection{Needs of Local Industries versus lacks of BC}

The importance conceded to needs of industry for taking account it in different components of SC and OC such as practical pre-professional, course work, contents of seminars, etc., was submitted to consideration. The criterions are presented in the figure $4 \mathrm{a}$. As can be observed, the experts of industries assigned the greatest importance to this problem (more than $70 \%$ evaluate with the highest rate). Professors and students also conferred it a high significance to this question.

In relating to deficiencies identified in the $\mathrm{BC}$, the greatest divergence is noted in the opinion of professors. Almost $50 \%$ of professors assess this aspect at rate 3 . Apparently, it is surprising but the professors justified this position considering that such contents can be transferred to post-grade courses. 


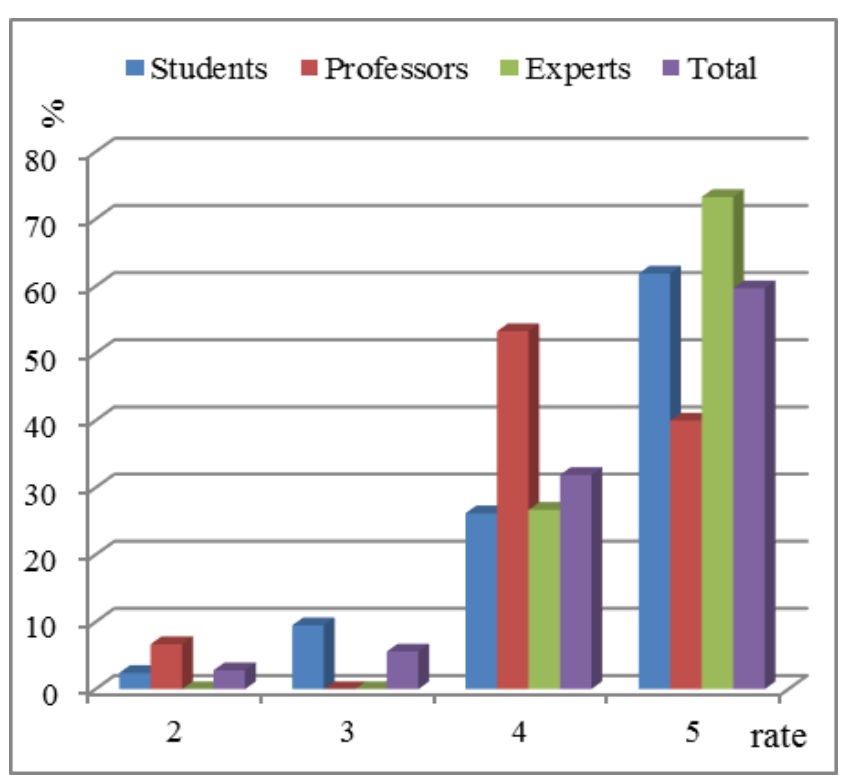

Figure 4a. Importance of including local industries needs in SC and OC

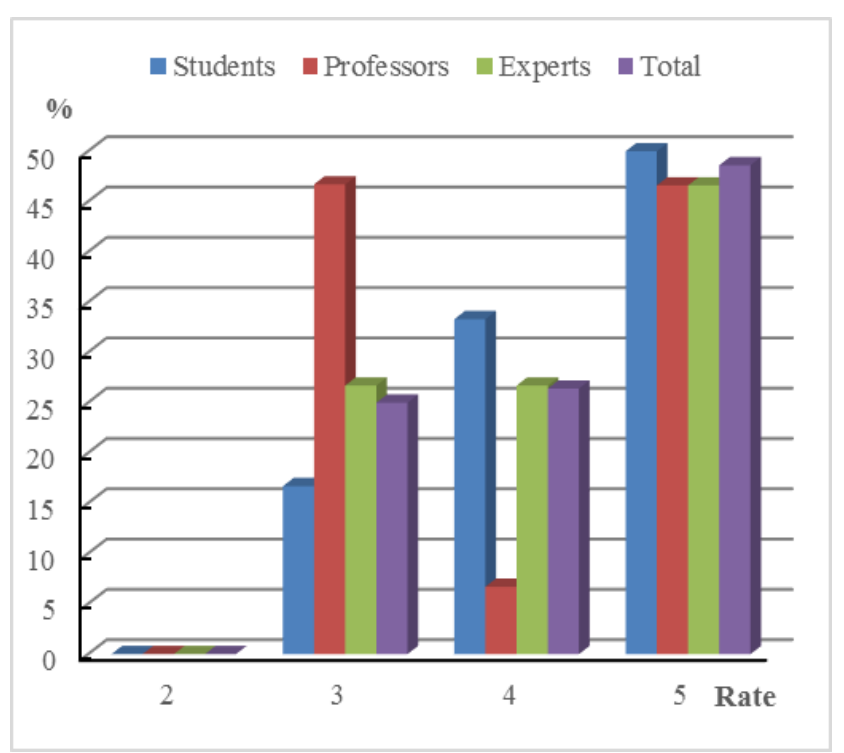

Figure 4b. Importance of incorporating the deficient contents in BC

\subsection{Consideration of Foreign and National Programs for SC and OPC Curricula}

The foreign programs under consult were: Curriculum Guide for undergraduates, University of Wisconsin Madison [18]; Chemical Engineering Catalog, University of Texas [19]; Bachelor of Science in Chemical Engineering /Course 10, MIT Course Catalog 2014-2015 [20]; White Book of Chemical Engineering Degree, European Convergence Program, 2005 [21].

The programs consulted of Cuban universities were: University of Oriente: The first program of Chemical Engineering opened in Cuba [22]; Polytechnic University of Havana [23]: The greatest center in which is developed the Chemical Engineering Undergraduate Program; Central University of Santa Clara [24].

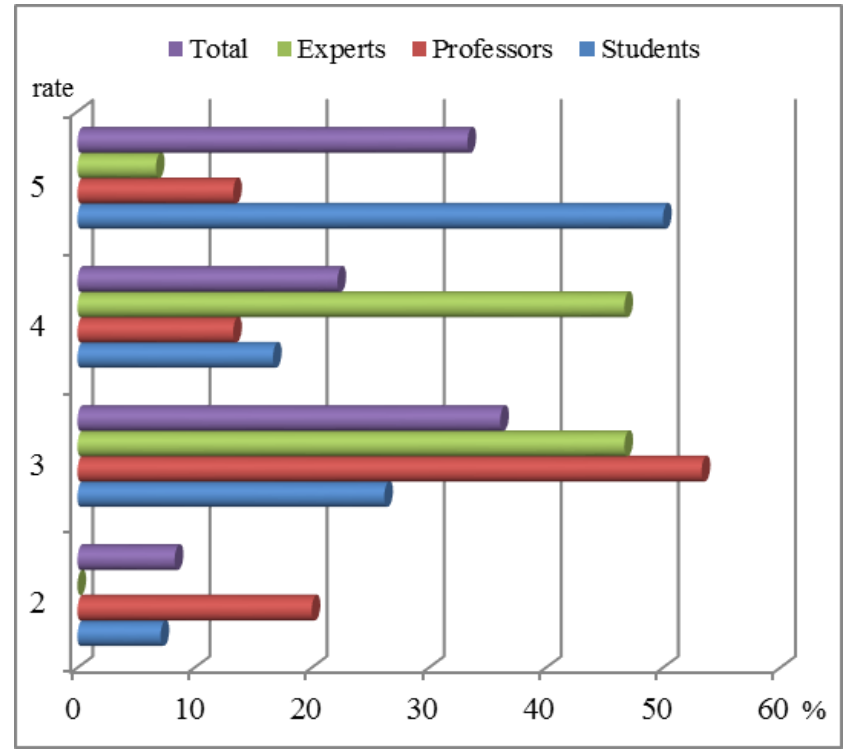

Figure 5. Foreign Curricula

Figure 5 reveals that curiously, the students are ahead in the scale about the degree of very adequate to consider the foreign programs. Later interviews reveal the importance conceded by them to academic equivalence.

On the other hand, the professors judge the differences in context as a very important factor. This view is supported in greater degree by the experts of industries. Nevertheless, all the participants recognize the importance of convergence in curricular matter in the Latin-American universities and the difficult for achieving it. At the other hand, it was stated the poor relationships with the universities of Anglo-Saxon world for a lot of reasons from access to information to idiomatic barriers.

As can be observed in the table 3 the Technologic University of Havana inclines its offers to context needs (Havana has an important Biotechnology Pole), Central University and University of Orient present proposals, which include the three areas: for strengthening of curricular contents, contextual requirements and environmental matters.

Table 3. SC and OC of UOP in Cuban universities

\begin{tabular}{|l|}
\hline Oriente \\
SC: UOP for management of atmospheric contaminants and toxic \\
residuals. \\
OC: UOP for separation in miner-metallurgic industry and solids \\
treatment, Special systems in absorption processes. \\
\hline Santa Clara \\
SC: New technologies and processes of separations. \\
OC: Methods of contamination prevention. \\
Basics operations of Food Industry. \\
\hline Havana \\
SC: Operations for Bioprocesses. \\
OC: Integration of Heat Transfer, Operations of biomolecules \\
separation.
\end{tabular}

When below we try to identify subjects relating to UOP, at the same time we recognize the deep interdisciplinary character of these matters. Besides, we should to accept that 
any analysis has as limitation, the diversity of the terms used and finally the variety of approaches in elective curriculum.

The selection of the American Universities presented in the table 4 doesn't respond at level of ranking, but to availability and direct form of declaring it. In every elective courses identified can be noted the presence of Environmental Engineering subjects and Bioprocess Engineering issues. Furthermore, frequently appear subjects associated to Food Engineering Operations, and New Product and Process Development. Truly is only a partial vision of the trends observed.

Table 4. Elective subjects associated to UOP in some American Universities

\begin{tabular}{|l|}
\hline Iowa \\
Chemical Process Engineering, Energy and Environment, \\
Sustainability, Biochemical Engineering, Pharmaceuticals. \\
\hline Wisconsin-Madison \\
Biological Systems Engineering, Food Engineering Operations, Food \\
and Pharmaceutical Separations, Environmental Engineering. \\
\hline Washington University in St. Louis \\
Sustainable Air Quality, Process and Product Design, Chemical Process \\
Safety, Bioprocess Engineering. \\
\hline
\end{tabular}

Finally, we consider the proposals of some Spanish Universities for two reasons: the historic influence on the Latin American Universities and the possibility of bring us to the trends of European Universities. Obviously, an important group of subjects are oriented to Environmental Engineering issues (Table 5).

Table 5. Optative subjects associated to UOP in some Spain Universities

University of Granada. OPTATIVE Total (12)
Food Industry, Treatment of solids and gas residues, Technolog
water treatment, Biochemical Engineering.
University of Málaga. OPTATIVE Total (12)
Equipment fluid-mechanics, Project of industrial facilities,
Environmental Technology, Sustainable Refinery and Bio-refin
University of King "Juan Carlos". Optative Total (10)
Profile A: Oil and Energy
Oil-Chemical Plants, Polymers Engineering, Oil Technology.
Profile B: Oil and Energy. Optative Total (10)
Treatment of waters waste, Management of industrial residues,
Atmospheric contamination.

\subsection{The Importance of Environmental Problems in the Subjects of UOP Disciplines in SC and OC Curricula}

When this matter was submitted to assessment, we didn't take into account only the planetary emergence of environmental problems. Cienfuegos, for its excellent harbor, rivers that surround it and its position in the central area of the island, was among the regions which underwent a faster industrial development in Cuba during sixties and seventies years of past century. In dialectical contradiction, the environmental price of this progress in the material sphere was high and in the last years of the 20th Century this situation became much more serious. For this reason, most of the problems to be solved in the local industry are related to environmental problems. Of course, these are not the unique concerns of the industrial sector. As result of the deep economic crisis in previous years, the innovation processes appear equally in today's agenda.

The figure 6 reflects the importance consigned to environmental problems through the different curricular components of UOP discipline from pre-professional practice of students in the industries to work course and thesis programmed. The experts of industries gave the highest significance. Both, students and professors also assign high importance to this problem, which is reflected in the high \% that gave it a big rate ( $80 \%$ between 4 and 5).

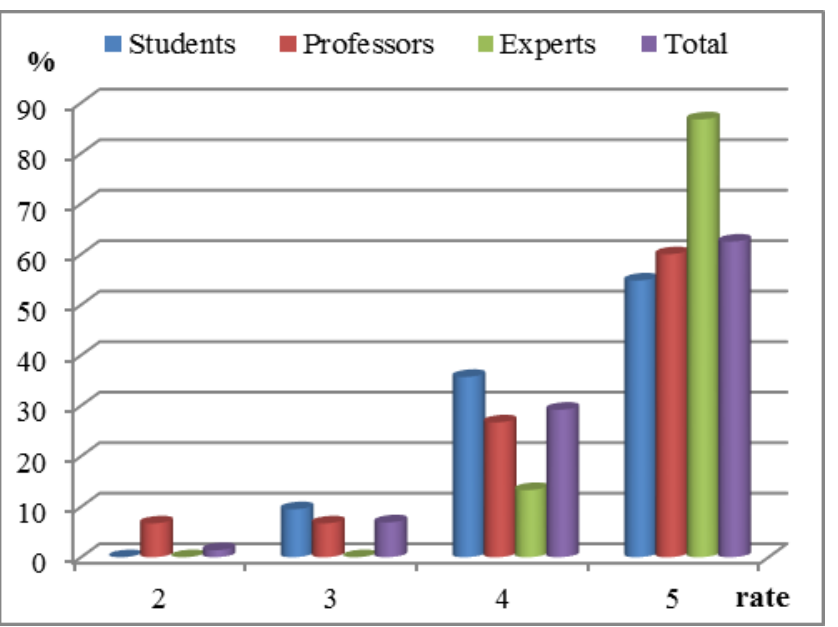

Figure 6. Importance of incorporating environmental problems in SC and OC

The table 6 shows the preferences of students of 4th and 5 th courses for the research lines offered on their Thesis. In each column is shown the percentage of students that considers as very adequate (v.a.), quite adequate (q.a) or adequate the main research themes associated with environmental problems in the local industries. These preferences have a double motivation: economical and professional ones. The preferential orientation to researches in the touristic sector has mainly an economical reason. Other predilections are related with the possibilities of insertion in the local and national labour market.

Table 6. Preferences of students in environmental issues. Range of valuation

\begin{tabular}{|c|c|c|c|}
\hline Research & v.a. (\%) & q.a. (\%) & a. (\%) \\
\hline Water and Waste Treatment & 62 & 28 & 10 \\
\hline Reduction of industrial emissions & 31 & 59 & 10 \\
\hline $\begin{array}{c}\text { Projects of improvement based in } \\
\text { Clean Production System }\end{array}$ & 59 & 28 & 13 \\
\hline $\begin{array}{c}\text { Ecological Management System } \\
\text { in tourism environments. }\end{array}$ & 66 & 31 & 3 \\
\hline $\begin{array}{c}\text { Projects of innovation based in } \\
\text { enhancement of UOP }\end{array}$ & 53 & 37 & 10 \\
\hline $\begin{array}{c}\text { Dust collection and purification of } \\
\text { gases methods }\end{array}$ & 47 & 34 & 19 \\
\hline $\begin{array}{c}\text { Design of plants for alternatives } \\
\text { energy generation. }\end{array}$ & 34 & 53 & 13 \\
\hline
\end{tabular}




\subsection{The Expert's Opinions by Means of Delphi Method}

The assessment of experts was applied in two moments of this study:

1. Initially, the methodology was submitted to evaluation. The experts in this first step received a general information about purposes and main tasks. Later was applied the round for obtaining and processing their criterions.

2. Finally, the results were presented them and after the experts assessed the adequacy of the proposed courses.

The tables 7 and 8 record the results of the latest statistical step. The statistical parameters offered are: The frequency observed for each aspect in the categories considered (I, NVA, A, QA, VA) according to valuation of experts; the cutoff points for each category, results obtained from the averages of the inverse normal distribution corresponding to each relative accumulative frequency for category $(\mathrm{C} 1, \mathrm{C} 2$, $\mathrm{C} 3, \mathrm{C} 4)$, the averages of the inverse normal distribution corresponding to each relative accumulative frequency for aspect $(\mathrm{P})$, and the values of points associated to (N-P) which define the category assigned for each aspect.

Experts should assess the complete list of the principles, procedures, tasks and indicators of the methodology. To simplify the data is not detailed opinion for each item but experts could express any judgment on the aspects considered.

The qualification given in the table 7 of very adequate only was achieved for "Principals and Procedures". Two experts indicated that the students of 3th course haven't the necessary knowledge for being considered participant in this evaluation. In relating with the main tasks, three experts considered that a narrow correlation between UOP in the local industries and those contained in the BC shouldn't be established. Finally, one expert point to the necessity of take account as an important indicator the prospective demand of each professional profile according to strategic development of our province.

The authors consider as polemic but reasonable these concerns and, of course, all were considered in this study.

The experts, with a high grade of agreement, assessed the selection of Environmental Technologies, and Biotechnology as very adequate and Petrochemical Technologies, Alternative Energy Generation, Cleaner Production Technology, Sugar and Derivatives Plants and Food Technology as quite adequate and in this order (Table $8)$.

Their opinions given in interviews with a unique question (Why?) were based mainly in the following factors: Professional experience of professors and assistants of industrial sector; comparative strengths of science and technology projects in our Faculty; installations required existing in university and industrial laboratories; availability of digital library and learning platform; bibliographic resources; strategic local development. They did not declare order of priority in any case.

Table 7. Validation of methodology applied

\begin{tabular}{|c|c|c|c|c|c|c|c|}
\hline & $\mathrm{C} 1=-3,09$ & $\mathrm{C} 2=-3,09$ & $\mathrm{C} 3=-0,59$ & $\mathrm{C} 4=0,36$ & & & \\
\hline & $\mathrm{I}$ & NVA & A & QA & VA & N-P & P \\
\hline $\begin{array}{c}\text { Principles \& } \\
\text { Procedures }\end{array}$ & 0 & 0 & 3 & 4 & 5 & 0,3782 & $-1,6610$ \\
\hline Main Tasks & 0 & 0 & 3 & 5 & 4 & 0,3227 & $-1,6059$ \\
\hline Indicators & 0 & 0 & 4 & 4 & 4 & 0,2618 & $-1,5449$ \\
\hline
\end{tabular}

Table 8. Conclusions Selection of Subjects

\begin{tabular}{|c|c|c|c|c|c|c|c|c|}
\hline & $\mathrm{C} 1=-3,09$ & $\mathrm{C} 2=-3,09$ & $\mathrm{C} 3=-1,28$ & $\mathrm{C} 4=0,74$ & & & & Category \\
\hline & I & NVA & A & QA & VA & N-P & P & \\
\hline PCh & 0 & 0 & 2 & 6 & 4 & 0,3345 & $-1,6791$ & QA \\
\hline AE & 0 & 0 & 6 & 3 & 3 & 0.0317 & $-1,3763$ & QA \\
\hline ET & 0 & 0 & 0 & 4 & 8 & 1,0805 & $-2,4251$ & VA \\
\hline CP & 0 & 0 & 3 & 6 & 3 & 0,2003 & $-1,5450$ & QA \\
\hline SD & 0 & 0 & 5 & 7 & 0 & $-0,5195$ & $-0,8251$ & QA \\
\hline FT & 0 & 0 & 2 & 8 & 2 & 0,2003 & $-1,5450$ & QA \\
\hline BT & 0 & 0 & 0 & 5 & 7 & 1,0254 & $-2,3701$ & VA \\
\hline
\end{tabular}




\section{Conclusions}

The methodology proposed guarantees an ample participation of all members of educational process and assures the necessary harmony among the academic pertinence and the social pertinence of subjects for specific and optional curricula in our context.

The results obtained point up the importance of taking into account the needs of the local industrial, the lacks of basic curriculum and the promising technologies in context for designing the specific and optional curricula in Unit Operations and Processes discipline of undergraduate program of chemical engineering.

The combination of needs in the local industry with the concerns in environmental matter and the specific problems identified in our province determined the favorable criterions about the inclusion of subjects related to Environmental Technologies in Specific and Optional Curricula of Unit Operations and Processes discipline.

The revision of the main trends observed in the Optional Curriculum of Chemical Engineering Program of national and foreign universities reveals the presence of numerous subjects associated to Environmental Technologies.

A panel of experts assessed the relative importance of different UOP subjects in our context. Their criterions consign the highest significance to Environmental Technologies and Biotechnologies.

\section{REFERENCES}

[1] Horruitiner Silva, Pedro: Chapter VII. A new generation of Study Plans. In: The Cuban University: Model of professional formation. Monographic. Journal of University Pedagogy, Vol. XII No. 4, 192 p., 2007. (In Spanish). Retrieved from: http://cvi.mes.edu.cu/peduniv/index.php/peduniv/issue/view/ 65

[2] Dias Sobrinho, José: Chapter 3 Quality, pertinence and social responsibility of the Latin-American and Caribbean University. In: Trends of the Higher Education en Latin-American and Caribbean/ Editors: Ana Lúcia Gazzola y Axel Didriksson - IESALC-UNESCO, 2008. Retrieved from: http://www.iesalc.unesco.org.ve/

[3] Engineering Accreditation Commission: Criterion 5 Curriculum. Abet Self-Study Questionnaire. 2014-2015 Review Cycle, 2013. Retrieved from: http://www.abet.org/wp -content/uploads/2015/04/eac-self-study-questionnaire-20142015.doc

[4] Ministry of Higher Education: Characteristics of Studies Plan D (Fourth generation). Cuban Higher Education Edition. Havana, 2003

[5] Viera Bertrán René: Central Document of Study Plan. Undergraduate Chemical Engineering Program. National Commission (NCChE). Editor: Cuban Ministry of Higher Education. Santiago de Cuba, 2007.

[6] Villarruel Fuentes, Manuel. Quality in the Higher Education: A thoughtful analysis about their process management in the
Latin American Universities. Iberia American Journal about Quality, Efficiency and Change in Education, vol. 8, no.5, pp. 111- 118, 2010. Retrieved from: http://www.rinace.net/reice/ numeros/arts/vol8num5/art7

[7] Garcell Puyans Leonel, Viera Bertrán René: UOP Program. "D" Undergraduate Chemical Engineering Program. Guidelines of National Commission, p.194. University of Oriente. Higher Education Ministry Editor. Santiago de Cuba, 2007.

[8] Wankat, Phillip C. The History of Chemical Engineering and Pedagogy: The Paradox of Tradition and Innovation. Chemical Engineering Education, v43 n3 pp. 216-224, 2009. Retrieved from: http://www.nt.ntnu.no/users/skoge/prost/proc eedings/aiche-008/data/papers/P123638.pdf

[9] Kim Irene: Chemical Engineering: A rich and diverse history. CEP Magazine. An AIChE Publication, January, 2002, http://www.aiche.org/resources/publications/cep/2002/januar $\mathrm{y} /$ rich-and-diverse-history

[10] AIChE Panel: A century of triumphs: Ten lasting chemical engineering achievements - and 100 markers of chemical engineers' progress toward them. CEP Magazine. An AIChE Publication, November, 2008. Retrieved from: www.aiche.org/cep

[11] Engineering Technology Accreditation Commission: 2015 2016 Criteria for Accrediting Engineering Technology Programs. Retrieved from: http://www.abet.org/wp-content/u ploads/2015/05/T001-15-16-ETAC-Criteria-05-04-15.pdf

[12] ABET: Student Outcomes. College of Engineering, Temple University. Retrieved from: https://engineering.temple.edu/en gineering-technology/accreditation

[13] Neville Postlethwaite, T.: Educational research: some basic concepts and terminology. UNESCO International Institute for Educational Planning. Series editor: Kenneth N. Ross, 2005 http://www.unesco.org/iiep/PDF/TR_Mods/Qu_Mod1.pdf

[14] De Miguel Diaz, Mario: Kinds of teaching centered in the development of competences (pp.194). Eds.: Ministry of Science and Education-University of Oviedo. Spain. 2005.

[15] González, Viviana; González, Rosa M.; López, Alejandro: Design of learning situations which promote professional competences in Higher Education. Journal Magister: Number 24, pp. 121-134, 2011. Spain. Retrieved from: https://dialnet.unirioja.es/descarga/articulo/3844478.pdf

[16] Horruitiner Silva Pedro: The challenge of the curricular transformations. Iberia American Journal of Education, no. 40/3, 13pp, 2006.

[17] Hurtado de Mendoza Fernández, Sandra: Expert's criterions, their processing through Delphi Method. Histodidactic. Universitat de Barcelona, 2012. Retrieved from: http://www.ub.edu/histodidactica/index.php?option=com_con tent $\&$ view $=$ article \&id=21: criterio-de-expertos-su-procesamie nto-a-traves-del-metodo-delphy\&catid=11:metodologia-y-epi stemologia\&Itemid=103

[18] Course Catalog 2014 - 2015, Bulletin. Chemical Engineering. Undergraduate Study. Course 10 (Ten). Massachusetts Institute of Technology, 2014. Retrieved from: http://web.mit.edu/catalog/degre.engin.ch10.html\#

[19] Chemical Engineering 2014-2016 Catalog (catalog valid until August 2022). University of Texas, 2014. Retrieved from: 
https://www.engr.utexas.edu/attachments/CHE\%2010\%20-\% 2012\%20Suggested\%20Courses\%20and\%20Flow\%20Chart. pdf

[20] Undergraduate Catalog 2015 - 2017. Chemical and Biological Engineering. University of Wisconsin-Madison. Retrieved from: http://pubs.wisc.edu/ug/engr_chembio.htm

[21] ANECA: White Book of Chemical Engineering Project of Chemical Engineer. Degree. European Convergence Program,
2005 Retrieved from http://www.aneca.es/media/150264/libr oblanco_ingquimica_def.pdf

[22] Garcell Puyans Leonel: UOP "D" Program. Chemical Engineering School. University of Oriente

[23] UOP "D" Program. Chemical Engineering School. Polytechnic University of Havana.

[24] UOP "D" Chemical Engineering Department. Central University of Santa Clara. 